\title{
Improvement of a gene targeting system for genetic manipulation in Penicillium digitatum ${ }^{* \#}$
}

\author{
Qian XU, Cong-yi ZHU, Ming-shang WANG, Xue-peng SUN, Hong-ye LI ${ }^{\dagger}$ \\ (Institute of Biotechnology, Zhejiang University, Hangzhou 310058, China) \\ ${ }^{\dagger} E$-mail: hyli@zju.edu.cn
}

Received Aug. 12, 2013; Revision accepted Dec. 6, 2013; Crosschecked Jan. 17, 2014

\begin{abstract}
Penicillium digitatum is the most important pathogen of postharvest citrus. Gene targeting can be done in $P$. digitatum using homologous recombination via Agrobacterium tumefaciens mediated transformation (ATMT), but the frequencies are often very low. In the present study, we replaced the Ku80 homolog (a gene of the non-homologous end-joining (NHEJ) pathway) with the hygromycin resistance cassette ( $h p h$ ) by ATMT. No significant change in vegetative growth, conidiation, or pathogenicity was observed in Ku80-deficient strain $(\triangle P d K u 80)$ of $P$. digitatum. However, using $\triangle P d K u 80$ as a targeting strain, the gene-targeting frequencies for both genes $P d b r l A$ and $P d m p k A$ were significantly increased. These results suggest that $K u 80$ plays an important role in homologous integration and the created $\triangle P d K u 80$ strain would be a good candidate for rapid gene function analysis in $P$. digitatum.
\end{abstract}

Key words: Penicillium digitatum, Efficiency, Gene targeting, Non-homologous end-joining (NHEJ) pathway, Ku80 doi: 10.1631 jzus.B1300213

Document code: A

CLC number: S436.661.1 $1^{+} 1$

\section{Introduction}

Penicillium digitatum (Pers.:Fr.) Sacc., causing a green mold in citrus, is the most destructive pathogen in the citrus industry and is responsible for the majority of decay losses of postharvest citrus (Eckert and Eaks, 1989; Kanetis et al., 2007; Macarisin et al., 2007). To date, a limited amount of information regarding the molecular mechanisms of pathogenesis is available for this important pathogen (Wang et al., 2012; Zhang et al., 2013a; 2013b; 2013c). The availability of genome sequence and genetic trans-

\footnotetext{
${ }^{\ddagger}$ Corresponding author

* Project supported by the National Natural Science Foundation of China (Nos. 31371961 and 31071649), the China Agriculture Research System (No. CARS-27), and the Special Fund for Agro-scientific Research in the Public Interest (No. 201203034), China

\# Electronic supplementary materials: The online version of this article (http://dx.doi.org/10.1631/jzus.B1300213) contains supplementary materials, which are available to authorized users

(C) Zhejiang University and Springer-Verlag Berlin Heidelberg 2014
}

formation has accelerated the progress in molecular biology of $P$. digitatum (Wang and Li, 2008; MarcetHouben et al., 2012; Sun et al., 2013).

Targeted gene knockout/replacement is an efficient and essential strategy for the functional characterization of interested genes in filamentous fungi. $P$. digitatum can be genetically transformed with a plasmid containing a selectable marker conferring resistance to antibiotics or herbicides via protoplast transformation of DNA (Hamamoto et al., 2000; Nakaune et al., 2002) or conidia transformation mediated by Agrobacterium tumefaciens (Wang and Li, 2008). However, the transformation via protoplast is usually very difficult for unknown reasons (our unpublished data) and the gene disruption frequency was very low $(<4 \%)$ or even negligible amongst transformants recovered through $A$. tumefaciens mediated transformation (ATMT) in many cases. This limitation greatly hampered the functional characterization of targeted genes in $P$. digitatum. 
Homologous recombination (HR) of exogenous DNA into the genome occurs easily in the yeast species, but it is not a ready mechanism for filamentous fungi since the non-homologous end-joining (NHEJ) pathway seems to be dominant over the HR pathway for repairing of DNA double-strand breaks (DSBs) in filamentous fungi (Ishibashi et al., 2006; Meyer et al., 2007; Maruyama and Kitamoto, 2008; Villalba et al., 2008). The DNA-dependent protein kinase complexes as well as a Ku70-Ku80 heterodimer are the central components of NHEJ (Haber, 2000; Jones et al., 2001). Previous studies indicated that destroying the NHEJ machinery by disrupting the $\mathrm{Ku} 70$ - or Ku80-coding gene could increase the gene-targeting frequency in a number of filamentous fungi, such as Aspergillus spp. (da Silva Ferreira et al., 2006; Nayak et al., 2006; Meyer et al., 2007; Chang, 2008; Maruyama and Kitamoto, 2008), Botrytis cinerea (Choquer et al., 2008), Magnaporthe oryzae (Villalba et al., 2008), Penicillium decumbens (Li et al., 2010), and Neurospora crassa (Ninomiya et al., 2004). However, disruption of Ku70 in Alternaria alternata, the pathogenic fungus causing brown spots on citrus, did not apparently improve the efficiency of gene targeting (Wang et al., 2011). The objective of this study was to explore the new strategy for increasing the gene-targeting frequency in $P$. digitatum.

\section{Materials and methods}

\subsection{Fungal strains and culture conditions}

The wild strain PdKH8 of $P$. digitatum was obtained from infected citrus of Ponkan (Citrus reticulata Blanco) in Quzhou, Zhejiang Province, China. The strain was stored as conidial suspensions in $15 \%$ glycerol at $-80{ }^{\circ} \mathrm{C}$, and recovered on regular potato dextrose agar (PDA). Mycelium was obtained by inoculating $5 \mu \mathrm{l}\left(1 \times 10^{6}\right.$ conidia/ml $)$ in $150 \mathrm{ml}$ liquid potato dextrose broth (PDB), which was incubated on a rotary shaker at $160 \times g$ and $25{ }^{\circ} \mathrm{C}$. Conidia were harvested in sterile water from a 7-d-old culture by scrapping the culture with a sterile glass rod, and the desired conidial concentration was adjusted by counting cells using a haematocytometer.

\subsection{Cloning and analysis of $K u 80$ homolog in $P$. digitatum}

All oligonucleotide primers used in this study are listed in Table $\mathrm{S} 1$. The $P$. digitatum $\mathrm{Ku} 80$ ortholog, $P d K u 80$, was found by the BLASTp search of the genomic sequence of $P$. digitatum (Sun et al., 2013) using Ku 80 homolog from Aspergillus oryzae (AoKu80, BAE78503.1). The amplified fragments in this study were cloned into the vector pMD18-T (TaKaRa Biotech. Co., Dalian, China) and the absence of polymerase-derived errors was checked by DNA sequencing. The $P d K u 80$ sequence was submitted into the GenBank/EMBL/DDBJ database under accession No. KF019685.

\subsection{Construction of PdKu80, PdbrlA, and PdmpkA disruption vectors}

The $P d K u 80$ disruption vector was constructed by inserting the two flanking sequences of $P d K u 80$ into the up- or downstream side of the hygromycin resistance cassette $(h p h)$ in the vector pTFCM (Wang and $\mathrm{Li}, 2008$ ). The primers used to amplify the homologous arms were synthesized according to the genomic sequence of $P$. digitatum (unpublished data). Briefly, a 1.2-kb DNA fragment containing the upstream flanking sequence of $P d K u 80$ was amplified from the $P$. digitatum genomic DNA by polymerase chain reaction (PCR) using primers Ku80-up-F/ Ku80-up-R (Table S1 and Fig. 1a). After digestion with $K p n I$ and $S a c$ I restriction enzymes, the PCR fragment was inserted into the KpnI-SacI site of pTFCM to generate the plasmid pTFCM-Ku80-up. Subsequently, a $1-\mathrm{kb}$ fragment representing the downstream flanking sequence of the $P d K u 80$ gene was obtained using primers Ku80-down-F/Ku80down-R (Table S1 and Fig. 1a). After digestion with Spe I and $X h o$ I restriction enzymes, the PCR fragment was inserted into the SpeI-XhoI site of the plasmid pTFCM-Ku 80 -up to generate the $P d K u 80$ disruption plasmid pTFCM- $\triangle P d K u 80$ (Fig. 1a).

Before the construction of the $\triangle P d b r l A$ and $\triangle P d m p k A$ vectors, a plasmid pNEO1300 was constructed by removing $h p h$ and inserting the neomycin resistant gene (neo) into the multiple cloning sites (MCSs) in pCAMBIA1300 (CAMBIA, Canberra, 
Australia). The neo was amplified from plasmid pCA-neo (Jiang et al., 2011) using primer pair Trpcneo-BamHI/Trpc-neo- $X b a \mathrm{I}$ (Table S1). The sequences of brlA (PdbrlA, JX298844) and mpkA (PdmpkA, KF019686) homologs in $P$. digitatum were obtained from a genomic database (unpublished data). The construction of $\triangle P d b r l A$ and $\triangle P d m p k A$ plasmids followed the method described in the construction of a disruption vector of $\triangle P d K u 80$. Briefly, the up- and downstream flanking sequences $(0.7$ and $0.9 \mathrm{~kb}$, respectively) of PdbrlA were amplified using primers brlA-up-F/brlA-up-R and brlA-down-F/brlA-down-R (Table S1 and Fig. S1a), while the up- and downstream flanking sequences $(1.0$ and $0.9 \mathrm{~kb}$, respectively) of $P d m p k A$ were amplified using primers mpkA-up-F/mpkA-up-R and mpkA-down-F/mpkAdown-R (Table S1 and Fig. S2a). The amplified sequences were then ligated to the KpnI-BamHI and $X b a \mathrm{I}$-HindIII sites of pNEO1300 (Figs. S1a and S2a), respectively.

\subsection{Disruptions of PdKu80, PdbrlA, and PdmpkA in $P$. digitatum}

The constructed disruption plasmids were transformed into an A. tumefaciens strain AGL-1 by the electroporation method described by Wang and $\mathrm{Li}$ (2008). To disrupt $P d K u 80$ in $P$. digitatum, the procedure of ATMT was conducted as the method described previously (Wang and $\mathrm{Li}, 2008$ ). To disrupt PdbrlA and PdmpkA in PdKu80-disrupted strain $(\triangle P d K u 80)$ of $P$. digitatum, a similar approach was also used, but instead of hygromycin B, $67 \mu \mathrm{g} / \mathrm{ml}$ of neomycin was added into the PDA for the selection of the putative PdbrlA- or PdmpkA-disrupted transformants.

The disruptions of $P d K u 80, P d b r l A$, and PdmpkA in $P$. digitatum were identified by PCR and followed by a Southern blot. For identification of $\triangle P d K u 80$, primer pairs Ku80-up-F/Ku80-i-R, Ku80-up-F/Ku80i2-R, and Ku80-V-F/hph-R1 (Table S1 and Fig. S3) were used; for $\triangle P d b r l A$, primers brlA-i-F/brlA-i-R and brlA-V-F/brlA-V-R (Table S1 and Fig. S1b) were used; for $\triangle P d m p k A$, primers mpkA-i-F/mpkA-i-R and mpkA-V-F/mpkA-V-R (Table S1, Figs. S2b and S2c) were used. For Southern blot analysis, genomic DNA $(100 \mu \mathrm{g})$ was digested with $X h o \mathrm{I}$ for $24 \mathrm{~h}$, the fragments were separated on a $0.8 \%(\mathrm{w} / \mathrm{v})$ agarose gel, and transferred to a Nylon membrane (Millipore,
Billerica, MA, USA). The probes (Fig. 1a) were labeled by PCR using the primers of hph-F/hph-R2 and Ku80-down-F/Ku80-down-R (Table S1), respectively, with the PCR DIG probe synthesis kit I (Roche, Mannheim, Germany), according to the manufacturer's instruction. Aqueous hybridization was performed at $42{ }^{\circ} \mathrm{C}$ overnight and detected using the DIG luminescent detection kit (Roche) according to the manufacturer's instruction.

\subsection{Assays of vegetative growth and sporulation}

To determine the effect of the deletion of $P d K u 80$ on vegetative growth and sporulation, mycelial plugs $(0.5 \mathrm{~cm}$ in diameter) of both wild-type PdKH8 and $\triangle P d K u 80$ strains of $P$. digitatum were prepared and transferred on PDA, Czapek yeast extract agar (CYA), and oat agar (OA) plates as described previously (Zhang et al., 2009). The plates were incubated at $25{ }^{\circ} \mathrm{C}$ for $5 \mathrm{~d}$ on PDA, and for $8 \mathrm{~d}$ on CYA and OA. Sporulation was assayed at the same day as above, following the method described previously (Zhang et al., 2013b). The experiment was conducted twice with at least three replicates.

\subsection{Assay of the tolerance to salt stress}

To determine whether $P d K u 80$ is involved in the tolerance to salt stress, mycelial plugs $(0.5 \mathrm{~cm}$ in diameter) of both wild-type PdKH8 and $\triangle P d K u 80$ strains of $P$. digitatum were prepared and transferred on PDA plates supplemented with $0.5 \mathrm{~mol} / \mathrm{L} \mathrm{NaCl}$ and $\mathrm{KCl}$. The growth on PDA with a non-supplement of either $\mathrm{NaCl}$ or $\mathrm{KCl}$ was used as control. The plates were incubated at $25^{\circ} \mathrm{C}$ for $5 \mathrm{~d}$, and the colony diameter in each plate was measured. Three replicates were used for each strain and the experiments were repeated twice.

\subsection{Virulence assay}

Mature and un-wounded Ponkan fruits $(C$. reticulata) were wounded with a bunch of five needles (2-3 $\mathrm{mm}$ in depth). Conidial suspensions $\left(1 \times 10^{6}\right.$ conidia $\left./ \mathrm{ml}\right)$ of the wild-type PdKH8 and $\triangle P d K u 80$ of $P$. digitatum were collected from 7-d-old PDA plates. Three microliters of the conidial suspensions were added onto each wounded site. The inoculated citruses were incubated at room temperature and disease symptoms were observed daily, and the lesion diameters were recorded at Day 5 after 
inoculation. Thirty fruits were used for each strain and the experiment was repeated twice.

\section{Results and discussion}

\subsection{Identification and analysis of the putative $P d K u 80$ gene in $P$. digitatum}

An exhaustive search via the BLASTp program was made to identify the $K u 80$ homolog in the $P$. digitatum genome (http://www.ncbi.nlm.nih.gov/) using AoKu 80 gene (BAE78503.1) as a reference sequence. The gene was a bidirectional best hit with $A o K u 80$, shared the highest similarity with $A o K u 80$ ( $E$-value 0 , identity $68 \%$, similarity $82 \%, 718$ amino acids), and was assumed as the putative $P d K u 80$ (AGT79985.1) through conserved domain analysis using a Pfam database (Bateman et al., 2004). Results showed that the putative $P d K u 80$ gene was $2673 \mathrm{bp}$ in length, which contained 10 introns and encoded 712 amino acids.

The possible conserved functional domains, $\mathrm{Ku} 70 / \mathrm{Ku} 80 \mathrm{~N}$-teminal $\alpha / \beta$ domain (positions 6 to 190), Ku70/Ku80 $\beta$-barrel domain (positions 274 to 440), and $\mathrm{Ku} \mathrm{C}$ terminal domain (positions 590 to 710) were presented in this gene, suggesting that it was definitely a $K u 80$ gene in $P$. digitatum. Sequence alignment revealed that PdKu80 had 64\%, $46 \%, 45 \%$, and $41 \%$ identity to its homologs identified in A. oryzae (BAE78503.1), Verticillium albo-atrum (XP 003001068.1), Fusarium oxysporum (EGU85850.1), and Neurospora crassa (BAD16623.1), respectively.

\subsection{Creation of PdKu80-disrupted strain ( $\triangle P d K u 80)$}

$P d K u 80$ targeting plasmid was constructed by substituting the sequence encoding $P d K u 80$ with $h p h$ (Fig. 1a). The constructed targeting plasmid pTFCM$\triangle P d K u 80$ was transformed into the wild-type strain PdKH8 by the ATMT method. Eighty-three transformants selected from a hygromycin-contained medium were primarily identified by PCR with primer pairs, Ku80-up-F/Ku80-i-R and Ku80-up-F/Ku80i2-R (Fig. 1a and Table S1). With these primer pairs, the fragments of 1.5 and $1.9 \mathrm{~kb}$ were amplified from the PdKH8 and ectopic transformants, while none fragment could be amplified from the PdKu80disrupted mutants ( $\triangle P d K u 80$; Fig. S3a). To get a positive result, primer pair Ku80-V-F/hph-R1 (Fig. 1a and Table S1) was used to amplify a fragment of $2.2 \mathrm{~kb}$ from the $P d K u 80$-disrupted mutants, while none fragment could be amplified from the PdKH8 or ectopic transformants (Fig. S3b). Based on these PCR results, the transformants $\triangle P d K u 80-14, \triangle P d K u 80-22$, and $\triangle P d K u 80-25$ were identified as $\triangle P d K u 80 s$. Southern blot analysis using a probe specific to $h p h$ verified the insertion of $h p h$ (Fig. 1b), and the Southern blot analysis using a probe located at the $3^{\prime}$ region of $P d K u 80$ (Fig. 1a) indicated that additional (a)
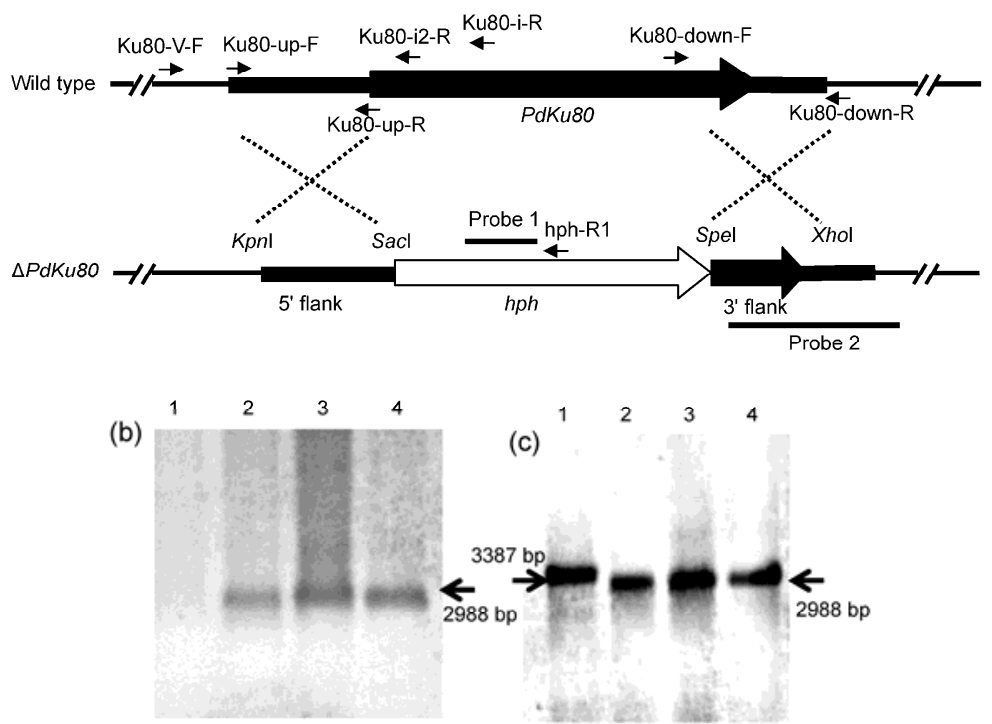

Fig. 1 Schematic diagram showing the construction of $P d K u 80$ disruption plasmid and molecular identification of $\triangle P d K u 80$ by Southern blot analysis

(a) Construction of $P d K u 80$ disruption plasmid. Black arrow represented the $P d K u 80$, while the white arrow represented a hygromycin resistance cassette $(h p h)$. The positions of the PCR primers were indicated with small arrows. Probes were indicated with black bars. (b) Identification by Southern blot using a probe specific to $h p h$. (c) Identification by Southern blot using a probe specific to the 3' part of the $P d K u 80$ gene. Lane 1: wild-type strain PdKH8; Lane 2: $\triangle P d K u 80-14$; Lane 3: $\triangle P d K u 80-22 ;$ Lane 4: $\triangle P d K u 80-25$ 
ectopic integration of the replacement cassette sequence did not occur in these transformants (Fig. 1c). The growth rates of three $\triangle P d K u 80 \mathrm{~s}$ were identical, and the data collected from $\triangle P d K u 80-25$ were presented hereafter.

\subsection{Disruption of $P d K u 80$ did not affect vegetative growth or sporulation}

Plate assay showed that the colony morphology of the $\triangle P d K u 80-25$ was identical to that of the wild-type strain PdKH8 on PDA, CYA, and OA media (Fig. 2a). The average colony diameter of $\triangle P d K u 80-25$ was slightly smaller than that of the wild-type strain PdKH8 on PDA; however, no significant difference was observed on CYA or OA $(P>0.05$; Figs. $2 \mathrm{a}$ and $2 \mathrm{~b}$ ). In addition, the sporulation of the $\triangle P d K u 80-25$ was similar to that of the wild-type strain PdKH8 on PDA, CYA, and OA media $(P>0.05$; Fig. $2 \mathrm{c})$. These results indicated that disruption of $P d K u 80$ did not affect vegetative growth or sporulation in $P$. digitatum.

\subsection{Disruption of $P d K u 80$ did not affect the toler- ance to salt stress}

The radial growths of $\triangle P d K u 80-25$ and the wild-type strain PdKH8 were compared on $\mathrm{NaCl}$ - and $\mathrm{KCl}$-contained PDA $(0.5 \mathrm{~mol} / \mathrm{L})$ to test the effect of $P d K u 80$ disruption on the tolerance of $P$. digitatum to salt stress. Compared with non-NaCl- and non-KClcontained PDA, the mycelial growth for both $\triangle P d K u 80-25$ and the wild-type strain PdKH8 was severely inhibited (about 60\%); however, the inhibition rates were similar for both strains, as indicated that the colony diameters for $\triangle P d K u 80-25$ and the wild-type strain PdKH8 were not significantly different $(P>0.05$; Fig. 3). This result indicated that the disruption of $P d K u 80$ did not affect the tolerance of $P$. digitatum to $\mathrm{NaCl}$ or $\mathrm{KCl}$ stress.

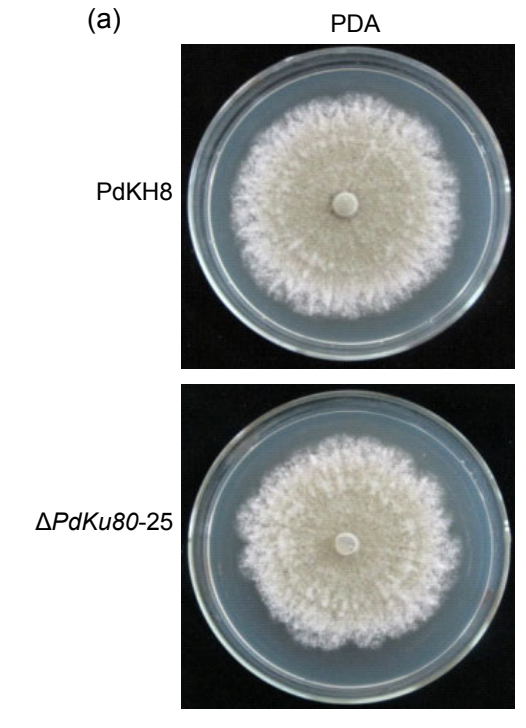

(b)

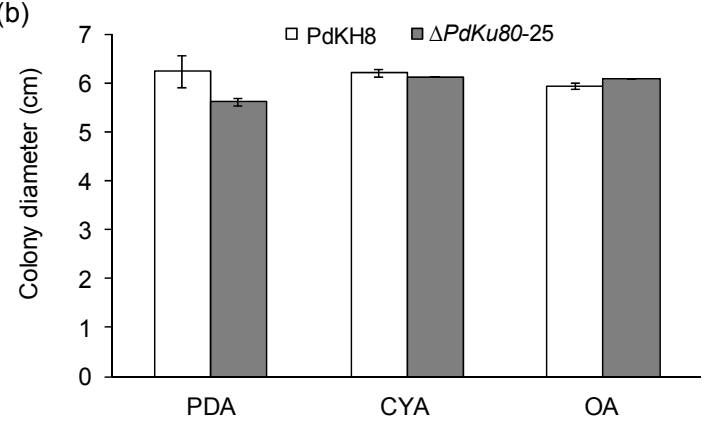

CYA
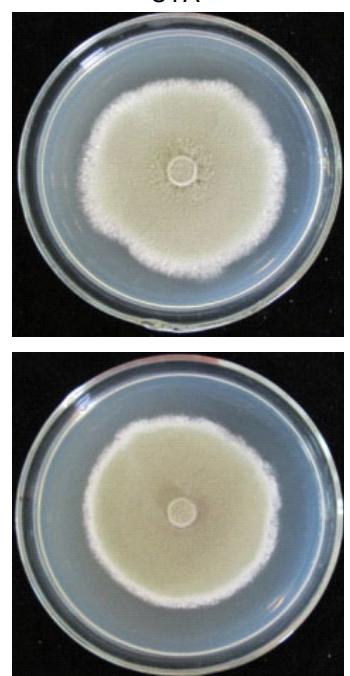

(c)
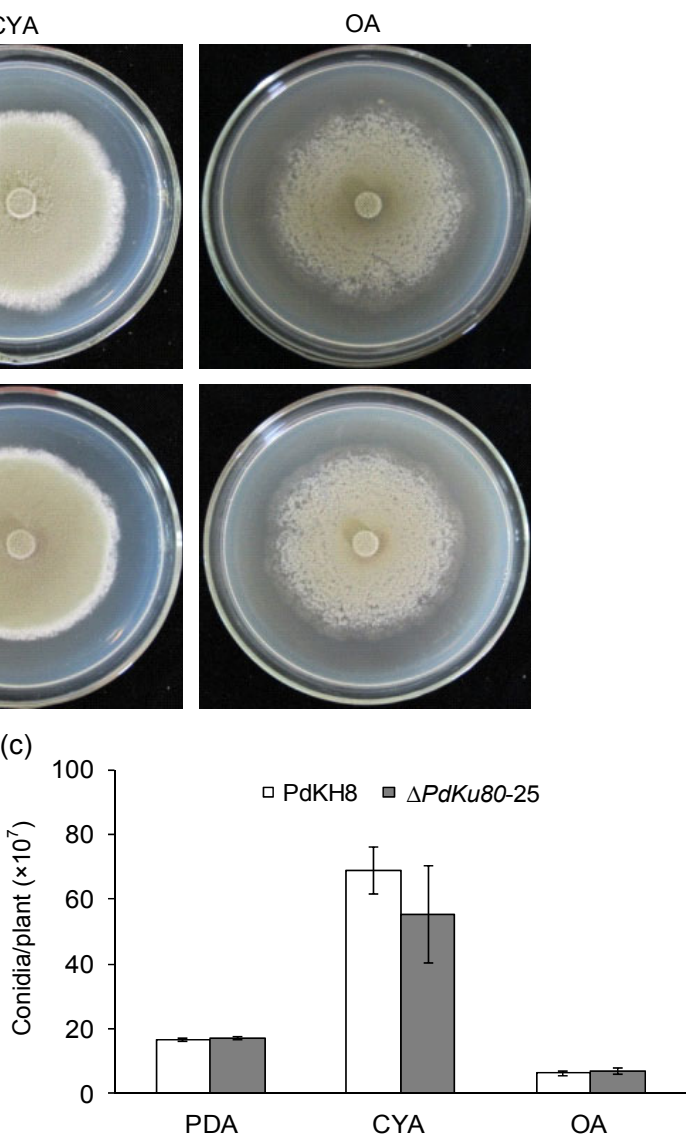

Fig. 2 Effect of disruption of $P d K u 80$ on the vegetative growth and sporulation

The results showed that disruption of $P d K u 80$ did not affect vegetative growth or sporulation. (a) The colonies of PdKH8 and $\triangle P d K u 80-25$ on PDA, CYA, and OA media. (b, c) Columns representing the average colony diameters and number of conidia and bars represented standard errors calculated from three independent colonies. Data were collected $5 \mathrm{~d}$ after incubation on PDA and $8 \mathrm{~d}$ on CYA and OA at $26^{\circ} \mathrm{C}$ 
(a)
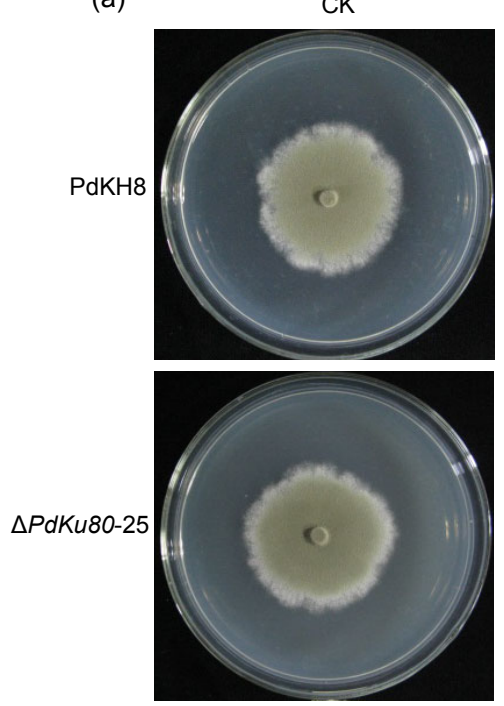

(b)

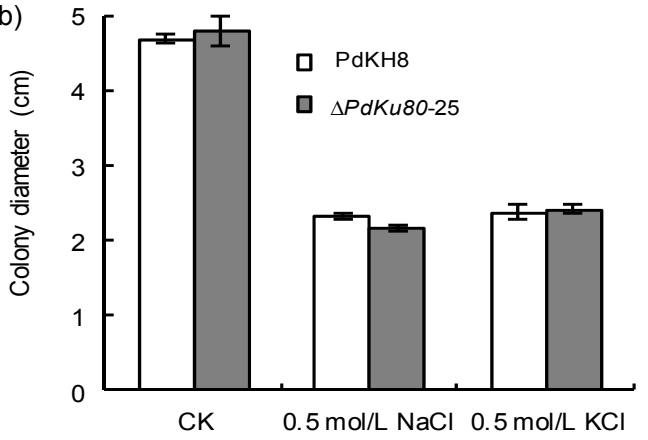

$0.5 \mathrm{~mol} / \mathrm{L} \mathrm{NaCl}$
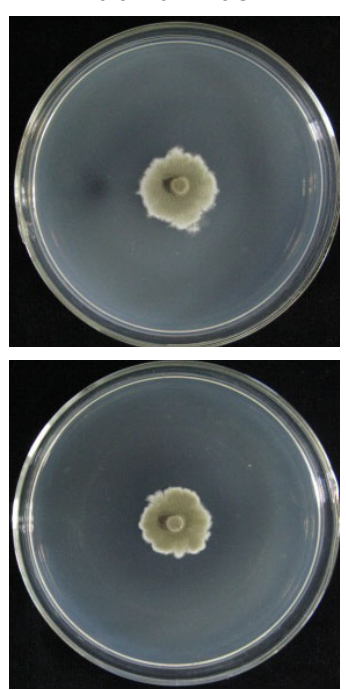

$0.5 \mathrm{~mol} / \mathrm{L} \mathrm{KCl}$
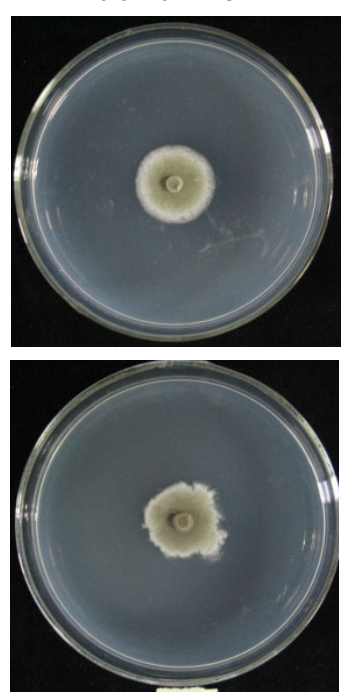

Fig. 3 Effect of disruption of $P d K u 80$ on the tolerance to salt stress

The results showed that disruption of $P d K u 80$ did not affect the tolerance to salt stress. (a) The colonies of PdKH8 and $\triangle P d K u 80-25$ on PDA with or without of $0.5 \mathrm{~mol} / \mathrm{L} \mathrm{NaCl}$ or $0.5 \mathrm{~mol} / \mathrm{L} \mathrm{KCl}$ at $5 \mathrm{~d}$ of incubation. (b) Columns representing the average colony diameters and bars representing the standard errors calculated from three independent colonies

\subsection{Disruption of $P d K u 80$ did not affect the virulence}

Pathogenicity assays on mature Ponkan fruits by inoculation of conidial suspensions of the $\triangle P d K u 80$ 25 and the wild-type strain PdKH8 revealed that the water-soaked lesion occurred on both strain-inoculated spots. At $5 \mathrm{~d}$ post-inoculation, the average lesion diameters caused by $\Delta P d K u 80-25$ and the wild-type strain PdKH8 were not significantly different $(P>0.05)$ (Fig. 4), indicating that disruption of $P d K u 80$ did not interfere with the virulence of $P$. digitatum to citrus.

\subsection{Disruption of PdKu80 improved gene target- ing efficiency}

The effect of the disruption of $P d K u 80$ on homologous gene targeting was evaluated by disrupting PdbrlA (JX298844) and PdmpkA (KF019686) genes in both $\triangle P d K u 80-25$ and the wild-type strain PdKH8 strains, respectively. The strategies for creating the $\triangle P d b r l A$ and $\triangle P d m p k A$ targeting cassettes were following the methods described in Section 2, and illustrated in Figs. S1a and S2a. The targeting cassettes of $\triangle P d b r l A$ and $\triangle P d m p k A$ were integrated into the strains of $\triangle P d K u 80-25$ and wild-type PdKH8 by ATMT, respectively. The putative transformants were selected on neomycin-contained media, and analyzed by diagnostic PCR. For $\triangle P d b r l A$, a $0.6-\mathrm{kb}$ fragment was able to be amplified from ectopic transformants but was not able to be amplified from $\triangle P d b r l A$ by primers brlA-i-F/brlA-i-R (Table S1 and Fig. S1b), which were located in the replaced region of PdbrlA (Fig. S1a); when using primers brlA-V-F/brlA-V-R (Table S1 and Fig. S1a), two fragments with sizes of 1.0 and $1.2 \mathrm{~kb}$ were amplified from ectopic mutants, while only the fragment of $1.2 \mathrm{~kb}$ was amplified from $\triangle P d b r l A$, and only $1.0 \mathrm{~kb}$ fragment was amplified from the wild-type strain of $P$. digitatum (Fig. S1c).

For $\triangle P d m p k A$, with primers mpkA-i-F/mpkA$\mathrm{i}-\mathrm{R}$ located in the replaced region of $P d m p k A$ 
(Table S1 and Fig. S2a), a 0.4-kb fragment was able to be amplified from the wild-type and ectopic transformants but could not from $\triangle P d m p k A$ (Fig. S2b). To get a positive result, primer pair mpkA-V-F/neo-R (Table S1 and Fig. S2a) was used to amplify a fragment of $2.0 \mathrm{~kb}$ from the mutants of $\triangle P d m p k A$, while no fragments could be amplified from the wild-type and ectopic transformants (Fig. S2c).

For disrupting genes $P d b r l A$ and $P d m p k A$, a total of 46 and 50 transformants, respectively, were picked up in the transformation experiment using wild-type PdKH8 as the targeting strain, and only 1 and 2 mutants were demonstrated to be PdbrlA- and PdmpkAdisrupted mutants, respectively, by diagnostic PCR. The efficiencies of PdbrlA and PdmpkA targeting were $2.2 \%$ and $4.0 \%$, respectively (Table 1 ). However, when using $\triangle P d K u 80-25$ as the targeting strain, the efficiencies of $P d b r l A$ and $P d m p k A$ targeting were $33.3 \%$ and $13.0 \%$, respectively (Table 1).

Targeted gene replacement requires the cellular machinery involved in the repair of DNA DSBs. There are two types of cellular machinery involved in DBS repair, the HR pathway and the NHEJ pathway (Kanaar et al., 1998). HR and NHEJ act independently and function competitively (van Dyck et al., 1999), thus making it possible to inactivate gene(s) of one pathway to favour another pathway. Ku70-Ku80 heterodimer and a catalytic subunit comprise a DNA-dependent protein kinase complex, which is the central component of NHEJ (Haber, 2000; Jones

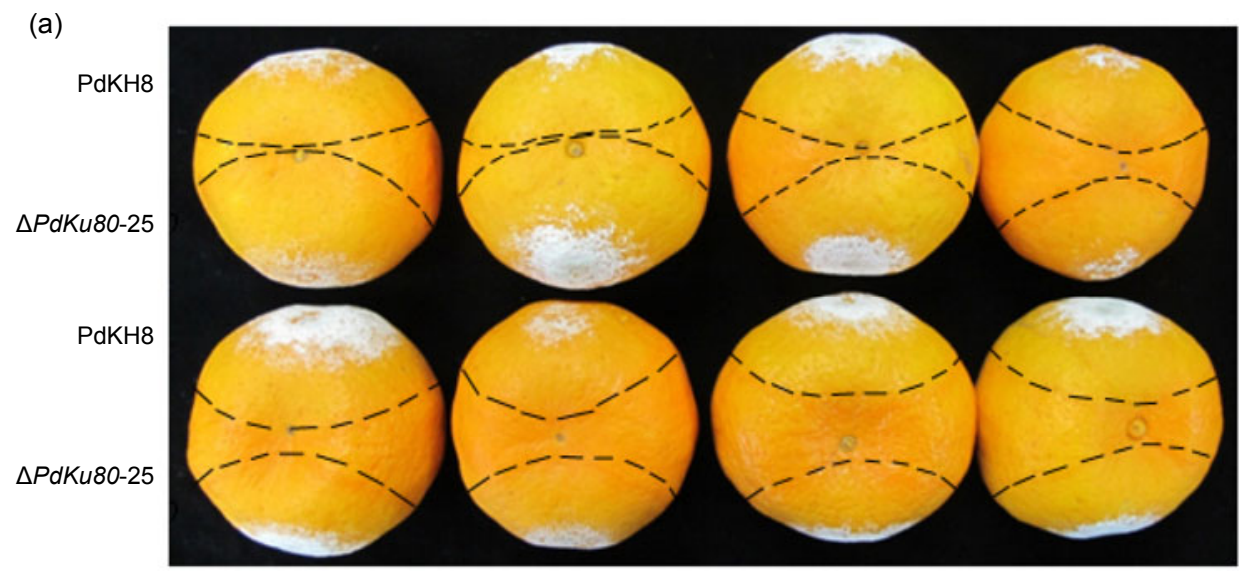

(b)

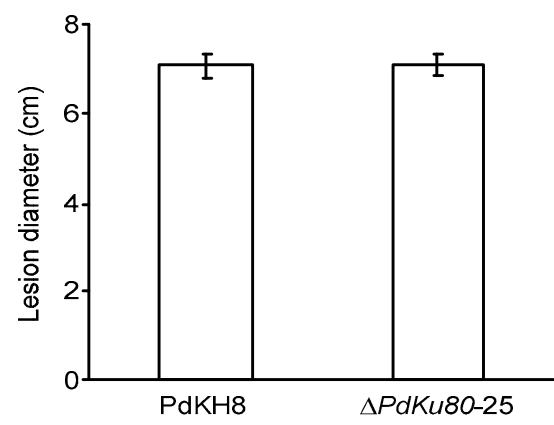

Fig. 4 Effect of disruption of $P d K u 80$ on the virulence The results showed that disruption of $P d K u 80$ did not affect the virulence. (a) Symptoms produced at $5 \mathrm{~d}$ after inoculation. (b) Columns represented the average lesion diameters and bars represented the standard errors calculated from three independent colonies, respectively

Table 1 Effect of $K u 80$ deletion on the efficiency of gene targeting in $P$. digitatum

\begin{tabular}{|c|c|c|c|c|c|c|}
\hline \multirow{2}{*}{$\begin{array}{l}\text { Targeting } \\
\text { strain }\end{array}$} & \multicolumn{3}{|c|}{ PdbrlA } & \multicolumn{3}{|c|}{ PdmpkA } \\
\hline & $\begin{array}{c}\text { No. of } \\
\text { transformants }\end{array}$ & $\begin{array}{c}\text { No. of knockout } \\
\text { mutants }\end{array}$ & $\begin{array}{c}\text { Targeting } \\
\text { frequency }(\%)\end{array}$ & $\begin{array}{c}\text { No. of } \\
\text { transformants }\end{array}$ & $\begin{array}{l}\text { No. of knockout } \\
\text { mutants }\end{array}$ & $\begin{array}{c}\text { Targeting } \\
\text { frequency }(\%)\end{array}$ \\
\hline PdKH8 & 46 & 1 & 2.2 & 50 & 2 & 4.0 \\
\hline$\triangle P d K u 80-25$ & 24 & 8 & 33.3 & 23 & 3 & 13.0 \\
\hline
\end{tabular}


et al., 2001). Inactivation of the NHEJ machinery by disrupting the Ku70- or Ku80-coding gene has been shown to increase HR in a number of filamentous fungi (Ninomiya et al., 2004; da Silva Ferreira et al., 2006; Krappmann et al., 2006; Nayak et al., 2006; Meyer et al., 2007; Chang, 2008; Choquer et al., 2008; Villalba et al., 2008; Li et al., 2010).

The frequency of gene targeting in $P$. digitatum via ATMT was always very low (our unpublished data). In the present study, the $K u 80$ homolog in $P$. digitatum was identified and its deficient mutant strain was generated. Our experiment showed that the deletion of $P d K u 80$ did not affect the basic biological characteristics, such as vegetative growth, sporulation, tolerance to salt stress, or pathogenicity, but significantly increased the gene targeting frequency in $P$. digitatum, suggesting that the created $\triangle P d K u 80$ strain can be used as a recipient strain for large-scale gene function characterization in $P$. digitatum. The generation of the $\triangle P d K u 80$ strain will expedite the progress in the functional genomic studies of this fungus.

\section{Compliance with ethics guidelines}

Qian XU, Cong-yi ZHU, Ming-shang WANG, Xue-peng SUN, and Hong-ye LI declare that they have no conflict of interest.

This article does not contain any studies with human or animal subjects performed by any of the authors.

\section{References}

Bateman, A., Coin, L., Durbin, R., et al., 2004. The Pfam protein families database. Nucl. Acids Res., 32(Suppl. 1): D138-D141. [doi:10.1093/nar/gkh121]

Chang, P.K., 2008. A highly efficient gene-targeting system for Aspergillus parasiticus. Lett. Appl. Microbiol., 46(5): 587-592. [doi:10.1111/j.1472-765X.2008.02345.x]

Choquer, M., Robin, G., Le Pêcheur, P., et al., 2008. Ku70 or $\mathrm{Ku} 80$ deficiencies in the fungus Botrytis cinerea facilitate targeting of genes that are hard to knock out in a wild-type context. FEMS Microbiol. Lett., 289(2):225-232. [doi:10. 1111/j.1574-6968.2008.01388.x]

da Silva Ferreira, M.E., Kress, M.R., Savoldi, M., et al., 2006. The $a k u B^{\mathrm{KU} 80}$ mutant deficient for nonhomologous end joining is a powerful tool for analyzing pathogenicity in Aspergillus fumigatus. Eukaryot. Cell, 5(1):207-211. [doi:10.1128/EC.5.1.207-211.2006]

Eckert, J.W., Eaks, I., 1989. Postharvest disorders and diseases of citrus fruits. Citrus Ind., 5:179-260.

Haber, J.E., 2000. Partners and pathways: repairing a double-strand break. Trends Genet., 16(6):259-264. [doi:10.1016/S0168-9525(00)02022-9]

Hamamoto, H., Hasegawa, K., Nakaune, R., et al., 2000.
Tandem repeat of a transcriptional enhancer upstream of the sterol 14 $\alpha$-demethylase gene (CYP51) in Penicillium digitatum. Appl. Environ. Microbiol., 66(8):3421-3426. [doi:10.1128/AEM.66.8.3421-3426.2000]

Ishibashi, K., Suzuki, K., Ando, Y., et al., 2006. Nonhomologous chromosomal integration of foreign DNA is completely dependent on MUS-53 (human Lig4 homolog) in Neurospora. PNAS, 103(40):14871-14876. [doi:10.1073/pnas.0604477103]

Jiang, J., Liu, X., Yin, Y., et al., 2011. Involvement of a velvet protein $\mathrm{FgVeA}$ in the regulation of asexual development, lipid and secondary metabolisms and virulence in Fusarium graminearum. PLoS ONE, 6(11):e28291. [doi:10.1371/journal.pone.0028291]

Jones, J.M., Gellert, M., Yang, W., 2001. A Ku bridge over broken DNA. Structure, 9(10):881-884. [doi:10.1016/ S0969-2126(01)00658-X]

Kanaar, R., Hoeijmakers, J.H., van Gent, D.C., 1998. Molecular mechanisms of DNA double-strand break repair. Trends Cell Biol., 8(12):483-489. [doi:10.1016/ S0962-8924(98)01383-X]

Kanetis, L., Förster, H., Adaskaveg, J.E., 2007. Comparative efficacy of the new postharvest fungicides azoxystrobin, fludioxonil, and pyrimethanil for managing citrus green mold. Plant Dis., 91(11):1502-1511. [doi:10.1094/PDIS91-11-1502]

Krappmann, S., Sasse, C., Braus, G.H., 2006. Gene targeting in Aspergillus fumigatus by homologous recombination is facilitated in a nonhomologous end-joining-deficient genetic background. Eukaryot. Cell, 5(1):212-215. [doi:10. 1128/EC.5.1.212-215.2006]

Li, Z.H., Du, C.M., Zhong, Y.H., et al., 2010. Development of a highly efficient gene targeting system allowing rapid genetic manipulations in Penicillium decumbens. Appl. Microbiol. Biotechnol., 87(3):1065-1076. [doi:10.1007/ s00253-010-2566-7]

Macarisin, D., Cohen, L., Eick, A., et al., 2007. Penicillium digitatum suppresses production of hydrogen peroxide in host tissue during infection of citrus fruit. Phytopathology, 97(11):1491-1500. [doi:10.1094/PHYTO-97-11-1491]

Marcet-Houben, M., Ballester, A.R., de la Fuente, B., et al., 2012. Genome sequence of the necrotrophic fungus Penicillium digitatum, the main postharvest pathogen of citrus. BMC Genomics, 13(1):646. [doi:10.1186/14712164-13-646]

Maruyama, J.I., Kitamoto, K., 2008. Multiple gene disruptions by marker recycling with highly efficient gene-targeting background $(\Delta l i g D)$ in Aspergillus oryzae. Biotechnol. Lett., 30(10):1811-1817. [doi:10.1007/s10529-008-9763-9]

Meyer, V., Arentshorst, M., El-Ghezal, A., et al., 2007. Highly efficient gene targeting in the Aspergillus niger kusA mutant. J. Biotechnol., 128(4):770-775. [doi:10.1016/j. jbiotec.2006.12.021]

Nakaune, R., Hamamoto, H., Imada, J., et al., 2002. A novel ABC transporter gene, PMR5, is involved in multidrug resistance in the phytopathogenic fungus Penicillium 
digitatum. Mol. Genet. Genomics, 267(2):179-185. [doi:10. 1007/s00438-002-0649-6]

Nayak, T., Szewczyk, E., Oakley, C.E., et al., 2006. A versatile and efficient gene-targeting system for Aspergillus nidulans. Genetics, 172(3):1557-1566. [doi:10.1534/ genetics.105.052563]

Ninomiya, Y., Suzuki, K., Ishii, C., et al., 2004. Highly efficient gene replacements in Neurospora strains deficient for nonhomologous end-joining. PNAS, 101(33): 12248-12253. [doi:10.1073/pnas.0402780101]

Sun, X., Ruan, R., Lin, L., et al., 2013. Genomewide investigation into DNA elements and ABC transporters involved in imazalil resistance in Penicillium digitatum. FEMS Microbiol. Lett., 348(1):11-18. [doi:10.1111/ 1574-6968.12235]

van Dyck, E., Stasiak, A.Z., Stasiak, A., et al., 1999. Binding of double-strand breaks in DNA by human Rad52 protein. Nature, 398(6729):728-731. [doi:10.1038/19560]

Villalba, F., Collemare, J., Landraud, P., et al., 2008. Improved gene targeting in Magnaporthe grisea by inactivation of MgKU80 required for non-homologous end joining. Fungal Genet. Biol., 45(1):68-75. [doi:10.1016/j.fgb. 2007.06.006]

Wang, J.Y., Li, H.Y., 2008. Agrobacterium tumefaciensmediated genetic transformation of the phytopathogenic fungus Penicillium digitatum. J. Zhejiang Univ.-Sci. B, 9(10):823-828. [doi:10.1631/jzus.B0860006]

Wang, J.Y., Sun, X.P., Lin, L.Y., et al., 2012. PdMfs1, a major facilitator superfamily transporter from Penicillium digitatum, is partially involved in the imazalil-resistance and pathogenicity. Afr. J. Microbiol. Res., 6(1):95-105.

Wang, N.Y., Yang, S.L., Lin, C.H., et al., 2011. Gene inactivation in the citrus pathogenic fungus Alternaria alternata defect at the Ku70 locus associated with non-homologous end joining. World J. Microbiol. Biotechnol., 27(8):1817-1826. [doi:10.1007/s11274-010-0640-z]

Zhang, T., Xu, Q., Sun, X., et al., 2013a. The calcineurinresponsive transcription factor Crzl is required for conidation, full virulence and DMI resistance in Penicillium digitatum. Microbiol. Res., 168(4):211-222. [doi:10.1016/j.micres.2012.11.006]

Zhang, T., Sun, X., Xu, Q., et al., 2013b. PdSNF1, a sucrose non-fermenting protein kinase gene, is required for Penicillium digitatum conidiation and virulence. Appl. Microbiol. Biotechnol., 97(12):5433-5445. [doi:10.1007/ s00253-012-4593-z]

Zhang, T., Sun, X., Xu, Q., et al., 2013c. The pH signaling transcription factor PacC is required for full virulence in Penicillium digitatum. Appl. Microbiol. Biotechnol., 97(20):9087-9098. [doi:10.1007/s00253-013-5129-x]

Zhang, Z., Zhu, Z., Ma, Z., et al., 2009. A molecular mechanism of azoxystrobin resistance in Penicillium digitatum UV mutants and a PCR-based assay for detection of azoxystrobin-resistant strains in packing- or store-house isolates. Int. J. Food Microbiol., 131(2-3):157-161. [doi:10. 1016/j.ijfoodmicro.2009.02.015]

\section{List of electronic supplementary materials}

Table S1 PCR primers used in this study

Fig. S1 Schematic diagram showing the construction of PdbrlA plasmid and identification of $\triangle P d b r l A$ transformants by PCR

Fig. S2 Construction of $P d m p k A$ disruption plasmid and identification of $\triangle P d m p k A$ transformants by PCR

Fig. S3 Identification of $\triangle P d K u 80$ by PCR

\section{中文概要:}

\section{本文题目：一种高效的柑橘绿霉菌基因敲除体系的构建}

Improvement of a gene targeting system for genetic manipulation in Penicillium digitatum

研究目的: 提高柑橘绿需菌基因敲除效率。

创新要点：低效的基因敲除与丝状真菌非同源末端链接（NHEJ）的 DNA 双链断裂修复途径有关。为提 高柑橘绿霉病菌基因敲除效率, 本研究利用农杆菌介导的转化体系, 获得 NHEJ 途径中关键 因子 $K u 80$ 的缺失突变体 $(\Delta P d K u 80)$ 。

研究方法: 与野生型菌株相比, 以 $\Delta P d K u 80$ 作为出发菌株, 提高柑橘绿霉病菌 PdbrlA 和 PdmpkA 的基 因敲除效率（见表 1)。

重要结论: $\Delta P d K u 80$ 的营养生长、产狍和致病性与野生型菌株基本一致。 $\Delta P d K u 80$ 作为出发菌株, 能显 著提高柑橘绿霉菌的敲除效率。

关键词组：指状青霉；基因敲除；非同源末端链接（NHEJ）；Ku 80 